\title{
SOME BMO ESTIMATES FOR VECTOR-VALUED MULTILINEAR OPERATORS
}

\author{
XIN-Sheng YuAN AND ZHI-GANG WANG
}

Abstract. In this paper, some $B M O$ endpoint estimates for certain multilinear integral operators are obtained. The operators include Littlewood-Paley operator, Marcinkiewicz operator and Bochner-Riesz operator.

Mathematics subject classification (2010): 42B20, 42B25.

Keywords and phrases: Vector-valued multilinear operator, Littlewood-Paley operator, Marcinkiewicz operator, Bochner-Riesz operator, BMO space.

\section{REFERENCES}

[1] S. Chanillo, A note on commutators, Indiana Univ. Math. J., 31 (1982), 7-16.

[2] W. CHEN AND G. Hu, Weak type $\left(H^{1}, L^{1}\right)$ estimate for multilinear singular integral operator, Adv. in Math. (China), 30 (2001), 63-69.

[3] J. CoHEN, A sharp estimate for a multilinear singular integral on $R^{n}$, Indiana Univ. Math. J., 30 (1981), 693-702.

[4] J. Cohen And J. Gosselin, On multilinear singular integral operators on $R^{n}$, Studia Math., 72 (1982), 199-223.

[5] J. Cohen And J. Gosselin, A BMO estimate for multilinear singular integral operators, Illinois J. Math., 30 (1986), 445-465.

[6] R. Coifman And Y. MEYer, Wavelets, Calderón-Zygmund and multilinear operators, Cambridge Studies in Advanced Math., 48, Cambridge University Press, Cambridge, 1997.

[7] R. COIFman, R. Rochberg And G. Weiss, Factorization theorems for Hardy spaces in several variables, Ann. of Math., 103 (1976), 611-635.

[8] Y. Ding AND S. Z. LU, Weighted boundedness for a class rough multilinear operators, Acta Math. Sinica, 17 (2001), 517-526.

[9] J. GARCIA-CuERVA AND J. L. Rubio DE FRAnCIA, Weighted norm inequalities and related topics, North-Holland Math., 116, Amsterdam, 1985.

[10] E. Harboure, C. Segovia And J. L. Torrea, Boundedness of commutators of fractional and singular integrals for the extreme values of $p$, Illinois J. Math., 41 (1997), 676-700.

[11] L. Z. LIU, Weighted weak type $\left(H^{1}, L^{1}\right)$ estimates for commutators of Littlewood-Paley operator, Indian J. of Math., 45 (2003), 71-78.

[12] L. Z. LIU, Endpoint estimates for multilinear Marcinkiewicz integral operators, East J. on Approximations, 9 (2003), 339-350.

[13] L. Z. LiU, Weighted Herz spaces continuity of multilinear opeartos for the extreme cases, Siberia Math. J., 45 (2004), 940-955.

[14] L. Z. LIU, Weighted continuity of multilinear Marcinkiewicz operators for the extreme cases of $p$, Commun. Korean Math. Soc., 19 (2004), 435-452.

[15] L. Z. LiU, Weighted endpoint estimates for multilinear Littlewood-Paley operators, Acta Math. Univ. Comenianae, 73 (2004), 55-67.

[16] L. Z. LIU, Weighted boundedness of multilinear operators for the extreme cases, Taiwanese J. Math., 10 (2006), 669-690.

[17] L. Z. LiU, Endpoint estimates for multilinear operators of some sublinear operators on Herz and Herz type Hardy spaces, Studia Sci. Math. Hungarica, 42 (2005), 131-151. 
[18] S. Z. Lu, Four lectures on real $H^{p}$ spaces, World Scientific, River Edge, NI, 1995.

[19] C. PÉREZ AND R. TRUJILlo-GonZALEZ, Sharp weighted estimates for vector-valued singular integral operators and commutators, Tohoku Math. J., 55 (2003), 109-129.

[20] E. M. STEIN, Harmonic analysis: real variable methods, orthogonality and oscillatory integrals, Princeton Univ. Press, Princeton NJ, 1993.

[21] A. Torchinsky, Real variable methods in harmonic analysis, Pure and Applied Math., 123, Academic Press, New York, 1986.

[22] A. Torchins KY AND S. WAng, A note on the Marcinkiewicz integral, Colloq. Math., 60/61 (1990), 235-243. 